\section{BMJ Global Health}

\title{
Advancing research on emergency care systems in low-income and middle- income countries: ensuring high-quality care delivery systems
}

\author{
Rachel T Moresky, ${ }^{1,2}$ Junaid Razzak, ${ }^{3}$ Teri Reynolds, ${ }^{4}$ Lee A Wallis, ${ }^{5}$ \\ Benjamin W Wachira, ${ }^{6}$ Mulinda Nyirenda, ${ }^{7,8}$ Waldemar A Carlo, ${ }^{9}$ Janet Lin, ${ }^{10}$ \\ Shama Patel, ${ }^{2}$ Sanjeev Bhoi, ${ }^{11}$ Nicholas Risko, ${ }^{3}$ Lily A Wendle (D) , \\ Emilie J Calvello Hynes, ${ }^{12}$ National Institute of Health Fogarty International Center \\ convened the Collaborative on Enhancing Emergency Care Research in LMICs \\ (CLEER)
}

\begin{abstract}
To cite: Moresky RT, Razzak J, Reynolds T, et al. Advancing research on emergency care systems in low-income and middleincome countries: ensuring high-quality care delivery systems. BMJ Glob Health 2019;4:e001265. doi:10.1136/ bmjgh-2018-001265
\end{abstract}

Handling editor Seye Abimbola

Received 29 0ctober 2018 Revised 7 February 2019 Accepted 8 February 2019
Check for updates

(c) Author(s) (or their employer(s)) 2019. Re-use permitted under CC BY-NC. No commercial re-use. See rights and permissions. Published by BMJ.

For numbered affiliations see end of article.

Correspondence to Dr Rachel T Moresky; rachel.moresky@columbia.edu

\section{ABSTRACT}

Emergency care systems (ECS) address a wide range of acute conditions, including emergent conditions from communicable diseases, non-communicable diseases, pregnancy and injury. Together, ECS represent an area of great potential for reducing morbidity and mortality in low-income and middle-income countries (LMICs). It is estimated that up to $54 \%$ of annual deaths in LMICs could be addressed by improved prehospital and facilitybased emergency care. Research is needed to identify strategies for enhancing ECS to optimise prevention and treatment of conditions presenting in this context, yet significant gaps persist in defining critical research questions for ECS studies in LMICs. The Collaborative on Enhancing Emergency Care Research in LMICs seeks to promote research that improves immediate and long-term outcomes for clients and populations with emergent conditions. The objective of this paper is to describe systems approaches and research strategies for ECS in LMICs, elucidate priority research questions and methodology, and present a selection of studies addressing the operational, implementation, policy and health systems domains of health systems research as an approach to studying ECS. Finally, we briefly discuss limitations and the next steps in developing ECS-oriented interventions and research.

\section{INTRODUCTION}

Since the adoption of the Sustainable Development Goals in 2015, there have been calls for more integrated, high-value approaches to healthcare delivery in low-income and middle-income countries (LMICs). Well-organised, integrated emergency care is a promising health platform; the Disease Control Priorities Project estimates that over half of the deaths in LMICs are from conditions that can be addressed by prehospital and

\section{Summary box}

Emergency care systems (ECS) are complex adaptive systems that present diverse research and intervention challenges, including appropriate research methodologies, funding, ethical considerations, conceiving and implementing a context-grounded programme design.

- 'Systems thinking' is employed to develop a research agenda and strategy for the study of ECS in low-income and middle-income countries (LMICs).

- Priority research questions and suggested methodology as well as a selection of studies addressing the operational, implementation and health systems domains of health systems research are presented.

- The proposed framework for ECS research offers evidence-based guidance to influence optimising health systems impact by decreasing morbidity and mortality from injuries and emergent conditions in LMICs.

facility-based emergency care. ${ }^{1}$ However, the current approach to emergency care suffers from severe fragmentation lacking systemwide coordination and accountability which contributes to reducing efficacy within a set of resources. ${ }^{2}$ There is also little research on which components of emergency care systems (ECS) have the greatest impact, ${ }^{3}{ }^{4}$ which mechanisms most effectively improve quality and expand access to critical services, ${ }^{5}$ or how to best match emergency care delivery to context. ${ }^{6-9}$ This paucity of research leaves policy-makers and planners with little guidance to inform resource allocation and effective programme development and assessment.

In July 2017, the National Institute of Health Fogarty International Center convened the 
Collaborative on Enhancing Emergency Care Research in LMICs (CLEER), including a subgroup on ECS. This subgroup was tasked to apply 'systems thinking' to identify key research gaps and questions with the potential to inform the development of effective, equitable and highquality emergency care, loosely defined for this discussion as the early, time-sensitive care provided for acute illness and injury. The results of prior consensus-based attempts to identify priorities for ECS research ${ }^{310}$ suggest many of the key unanswered questions in complex adaptive systems, such as ECS, are poorly suited to conventional interventional and implementation research methods. While these consensus papers address research agendas for both emergency care service delivery ${ }^{3}$ as well as emergency care and health systems in LMICs, ${ }^{9}$ no research framework for ECS has thus far been developed.

This manuscript draws on other fields of study, namely business operations management, education, econometrics and social sciences research to suggest other potential methods to investigate components of ECS. In doing so, we aim to (1) present a framework to assist research on ECS given the complexity of the system, (2) present key hitherto unanswered ECS research questions and (3) suggest the methodological approaches that can be taken to answer these questions. Many of the research methodologies discussed have not been applied to ECS yet, but the promising approaches and use in other fields are encouraging in providing possible research methodologies to study the efficacy and quality of ECS.

\section{BACKGROUND}

Health systems, according to the WHO, are all organisations, people and actions whose primary intent is to promote, restore and maintain health by improving health and health equity. ${ }^{11-13}$ The WHO Alliance for Health Systems and Policy Research has been working for two decades to promote 'systems thinking as a means to better understand health system behavior'. ${ }^{13}$ There is no consensus on an overall approach to 'systems thinking' or the implication in this specific context, but there are five complementary qualities within 'systems thinking' that elucidate its potential value for emergency care research, which are discussed below:

1. Emphasises the importance of an interaction between connected components, which is key to account for emergency care elements that are correlated and ideally coordinated with definitive care or other acute care services.

2. Allows a practical treatment of components that may be implemented in different ways across various contexts. This makes possible a comparative approach in which findings can be projected (even if only for hypothesis generation) across systems at very different levels of development. For example, the utilisation of a client-triggered ambulance service may have relevance to a sophisticated system with computerised call centre and global positioning system tracking as well as to a simpler system that uses mobile phones, grid maps and protocols.
One such example is the WHO Emergency Care System Framework. ${ }^{13} 14$

3. Enables routine and structured analysis of the feedback loops and process contexts that make ECS behaviour 'messy.'. 15 ECS tend to be multifaceted and unpredictable, reflecting the dynamic process of both positive and negative feedback loops. ${ }^{17} 18$ The implementation of emergency unit registries and surveillance are examples in which data collection approaches the status of an intervention, in that the feedback loop of gap identification, corrective action and ongoing monitoring has an impact well beyond any quantitative baseline and end-line analysis alone.

4. Permits evaluation of outputs and outcomes, even where a causal pathway from the intervention can be neither mapped nor tracked as it happens. Many examples exist of such 'path dependency' (a typical quality of complex systems) in emergency care. ${ }^{19}$ Triage is an example that is inadequately captured by traditional causal narratives, in which a single 'intervention' (triage implementation) shifts the relative position of many system elements (eg, how rapidly client receive interventions, how frequently reassessments are completed, how quickly a client is admitted to the intensive care unit, etc). ${ }^{15}$

5. Opens the possibility of network analysis, where any individual (node) within the system is characterised by its relative position and relationship to another node, ${ }^{20}$ rather than its inherent characteristics of the node itself. The nature of referral flow through the acute care system-one of the most under-researched areas of emergency carewould be highly amenable to social network analysis.

The goals of ECS research are (1) to improve understanding of what ECS are and how they operate, (2) to determine what interventions improve both the public health impact and address the wider social value of ECS, (3) to identify cost-effective interventions that can be integrated at different levels of ECS, and (4) to develop and implement interventions that achieve and enhance access to respectful, high-quality care and improve health outcomes. As the field of health policy and system research (HPSR) has grown, ECS analysis has underused HPSR approaches. Our proposed research framework for ECS adapts well-established health system frameworks $^{1421-28}$ to better understand system functions and the nature of their interaction in emergency care (see figure 1).

\section{THE FRAMEWORK FOR ECS RESEARCH}

In this framework, ECS can be understood as complex adaptive systems (CAS), collections of individual actors with freedom to act in ways that are often not predictable, and whose actions are interconnected, so that one agent's actions change the context for other agents. ${ }^{29} 30$ This model includes the following key elements:

1. A set of inputs and processes (building off of the WHO health systems building blocks ${ }^{14}$ leveraging the 


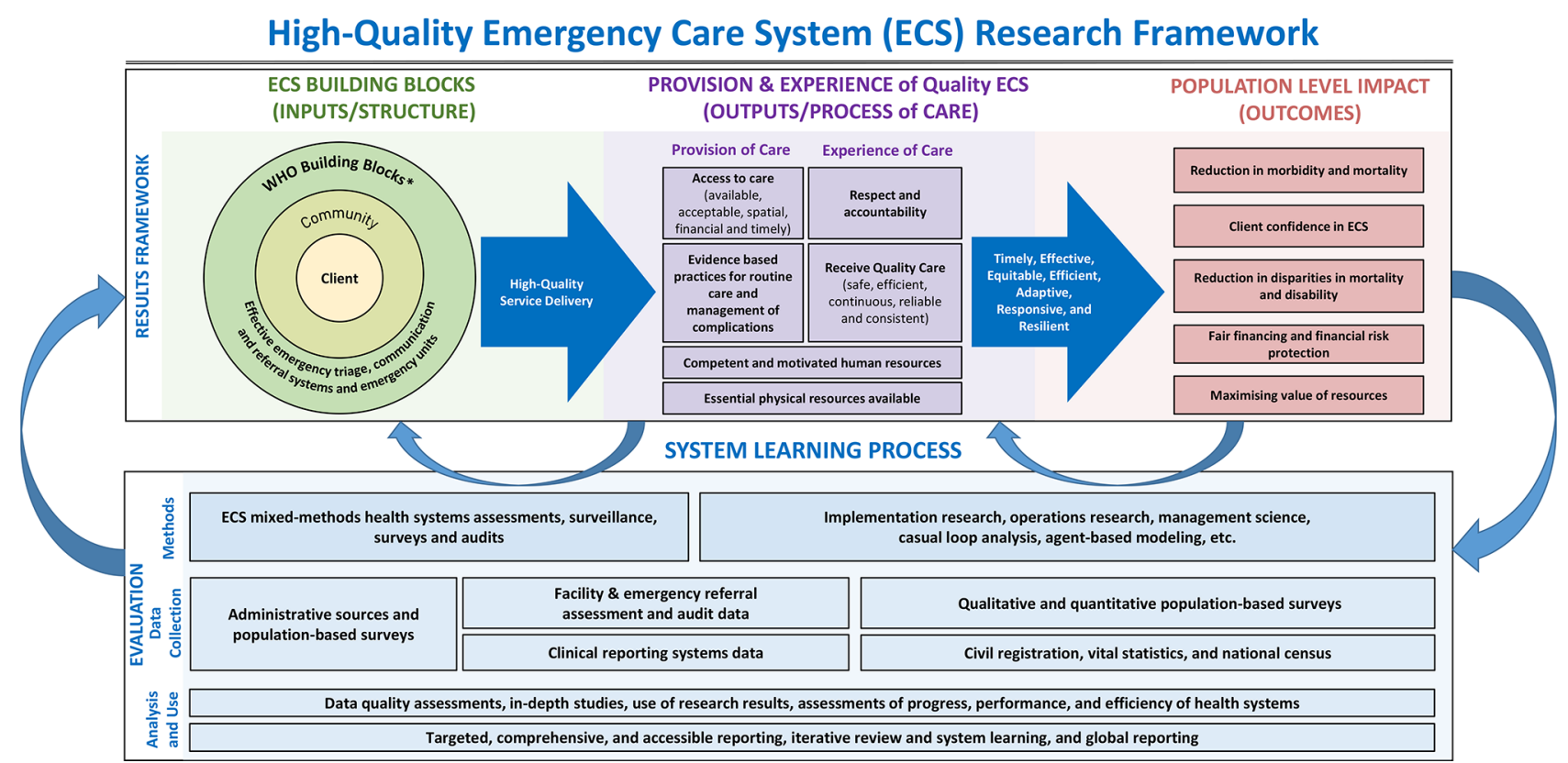

Figure 1 Framework for emergency care system research. ${ }^{813145 * W H O}$ building blocks: service delivery, health workforce, information, medical products, vaccines and technologies, financing, leadership/governance. Framework citation here: Tunçalp, Ö, et al. BJOG 122 (2015) 1045-49; Kruk M. Health Policy 85 (2008) 263-276; WHO global strategy on people-centered and integrated health services (2015); Kruk M. Lancet Glob Health (2018); 1196-252.

social-ecological model of a people-centred system. ${ }^{31}$ While difficult to represent, these components have a dynamic interplay which is heavily informed by access to, understanding and utilisation of information to make data-informed decisions. In addition to the traditional WHO building blocks, an ECS requires effective emergency triage, extensive communication and referral systems to ensure proper coordination, as well as management, mentoring and supportive supervision. ${ }^{1421} 29$ These inputs and processes are nested in an open system where there is a continuous interflow of components from both within and without the system. ${ }^{32}$

2. A population who require emergency health services and participate in emergency care outcomes via health-seeking and health-promoting behaviour developed in part through people-centred design. ${ }^{33} 34$ Placing informed and empowered people at the centre of the health system requires integrated health services which are accountable to local stakeholders and, especially, to marginalised and underserved populations. ${ }^{31}$ This is particularly relevant to emergency health services as many people with high barriers to access may only seek care when acutely ill or injured. ${ }^{31}$

3. The incorporation of various modes of emergency service delivery (eg, community first-response models, out-of-facility emergency care and facility-based emergency care) and a mixture of service providers (eg, formal and informal, public and private). ${ }^{835}$

4. The outcomes and impact presented in this framework focus on population-level improvements in morbidity and amenable mortality, ${ }^{36}$ client confidence in ECS, fair financing and optimising resource allocation to emer- gency care for vulnerable populations, and reduction in disparities in mortality and disability.

5. Data sources that can be used for operational, implementation and systems research by clients, frontline providers, managers and policy-makers. ${ }^{28}$ Techniques using health facility data can identify system readiness. Service delivery-based data audits can assess the quality of emergency care provided while population-based surveys evaluate health outcomes from emergency conditions. ${ }^{37}$ Empowered clients require a reciprocal relationship by being engaged in both understanding and using those data to maximise their health outcomes.

While health system domains and building blocks are a useful way to describe the 'hardware' of the system, ECS research must include social and economic determinants and the dynamic linkages between each component. ${ }^{38}$ Health systems performance is also profoundly influenced by systems 'software' or the values, norms, relationships, people and power of actors operating within and outside the system. ${ }^{39}$ Effective ECS research elucidates the non-linear, analogue and dynamic relationships between system software and the functional hardware system components. ${ }^{15} 38$

ECS, and thus research on ECS, operates at multiple levels. These include the macro-level architecture and oversight of the ECS (eg, global and national context, domestic health system), the meso-level functioning of emergency care organisation and interventions (eg, providers, health managers at the organisation and local level), and the micro level of the individual within the ECS (eg, community clients). ${ }^{36} 38$ 


\section{RESEARCH QUESTIONS, METHODOLOGY AND CONSIDERATIONS}

A short list of priority research questions has been identified by the CLEER working group.

Which components of the WHO ECS Framework have the most effect on improving client outcomes and decreasing amenable deaths ${ }^{40}$ for the acutely ill in LMICs? Multiple components exist within the ECS (see online annex 1) where some limited research has been done assessing specific components. For example, organising a low-cost prehospital system was associated with a substantial decrease in trauma mortality in Cambodia and Iraq. ${ }^{41}$ A prehospital care service improved access $^{42}$ and utilisation in Nepal. ${ }^{43} \mathrm{~A}$ review and meta-analysis of mortality in LMICs estimated a $25 \%$ reduction in risk of death from trauma in areas with prehospital trauma systems. ${ }^{40}$

What are the minimum packages of care that are most effective in synergising components of ECS by care context and the burden of acute disease to deliver high-quality care? Various models of ECS delivery have been implemented throughout the world. In Malawi, restructuring the hospital intake, dedicating an emergency care area and initiating formal triage were associated with a reduction in 24-hour death from $36 \%$ to $12.6 \%{ }^{44}$ In rural Mali, access to comprehensive emergency obstetric care reduced the risk of maternal mortality by half, lasting 2 years after the intervention. ${ }^{45}$

Which ECS indicators and surveys are most context appropriate and feasible to measure at a given level of development across the care continuum? Research should address capture rates within the ECS, accessibility to users, challenges to health equity and facilitators of ECS components. A review from LMICs identified barriers to prehospital care categorised into six themes: culture/community, infrastructure, communication/coordination, transport, equipment and personnel. ${ }^{4546}$

How can ECS design and integration efficiently optimise access, equity and outcomes while reducing unnecessary emergency visits? It is often said that every system is perfectly designed to get the results it gets. To operationalise the above research priorities, it will be important to identify the overall purpose and goals of the research; to whom and how will it be useful; how will it add to the existing knowledge base; and what different types of research will be used. ${ }^{47}$ Systems thinking and HSPR research models will lend well to this type of ECS research as CAS. ${ }^{11}$

While 'system thinking' provides a natural paradigm in which to understand ECS research, the operationalisation conducting research of ECS is more complicated and unclear. Finding pragmatic approaches to capturing dynamic interactions between systems components and causal loops requires a variety of multidisciplinary approaches. Implementation science iteratively collects data and provides feedback to stakeholders and into the system to more effectively promote evidence-based research into routine practice.

For other research questions, systems learning process may be evaluated. Depending on the specific research questions, settings and resources, study designs may include quasi-experimental designs (eg, econometric techniques like difference in difference, hybrid models) and pragmatic randomised control trials (RCTs) (step-wedge, cluster, comparative-effectiveness or interrupted time series). To address these priorities, researchers will need to use elements of clinical effectiveness, implementation and embedded research science. ${ }^{26384748}$ Comparative effectiveness designs are also useful to assess direct comparisons of existing healthcare interventions to determine which interventions pose the greatest benefits and least harms. Each of these study designs can provide insight into optimising ECS in LMICs. Table 1 outlines selected studies addressing the operational, implementation and health system domains of ECS research. ${ }^{27}$ The table outlines published studies on components of ECS with many focusing on training and education, triage development, lay provider prehospital training and trauma system implementation. ${ }^{41}$ To date, limited studies have been conducted on other components or the entire system.

More broadly, ECS are composed of complex adapting strategies and methodologies from different industries and fields of study are an important way to study interactions. For example, business operations research methods like queueing theory that look at the study of congestion and delays in waiting in line can help researchers study efficient and cost-effective patient workflows. (1) Implementation research is designed to assess natural variability and measure change in response to planned interventions which can investigate evidence-based applications in LMIC settings. (2) These typically require more transdisciplinary research teams and solid grounding in theory. Further, borrowing from social science and behavioural research methodology is warranted to understand different and/ or adaptation of recognised approaches. These typically demand more observational and ethnographic methods that are not possible with the traditional randomised control designed studies.

It is important to note that the study design must be tailored to a variety of settings and contexts. Settings including urban, rural, conflict and disasters all present unique challenges for the implementation of research. Furthermore, research into system-level interventions requires traditional clinical (process or outcome) impact measures but should ideally also address issues of cost-effectiveness which allows for ranking and prioritisation more holistically. Overall, there will not be a 'one size fits all' approach to studying ECS; instead, a complementary array of approaches should be considered that is context specific and provides the most robust data on cost-effectiveness, efficacy and quality, which will require a shift in thinking from traditional RCT approaches.

\section{LIMITATIONS}

ECS research is a multidisciplinary field focused on CAS which are continuously evolving and responding to an interdependent array of components. Some questions have recently come up regarding HPSR in general, including:

1. Who defines the research questions for ECS and what is the process for their design? 


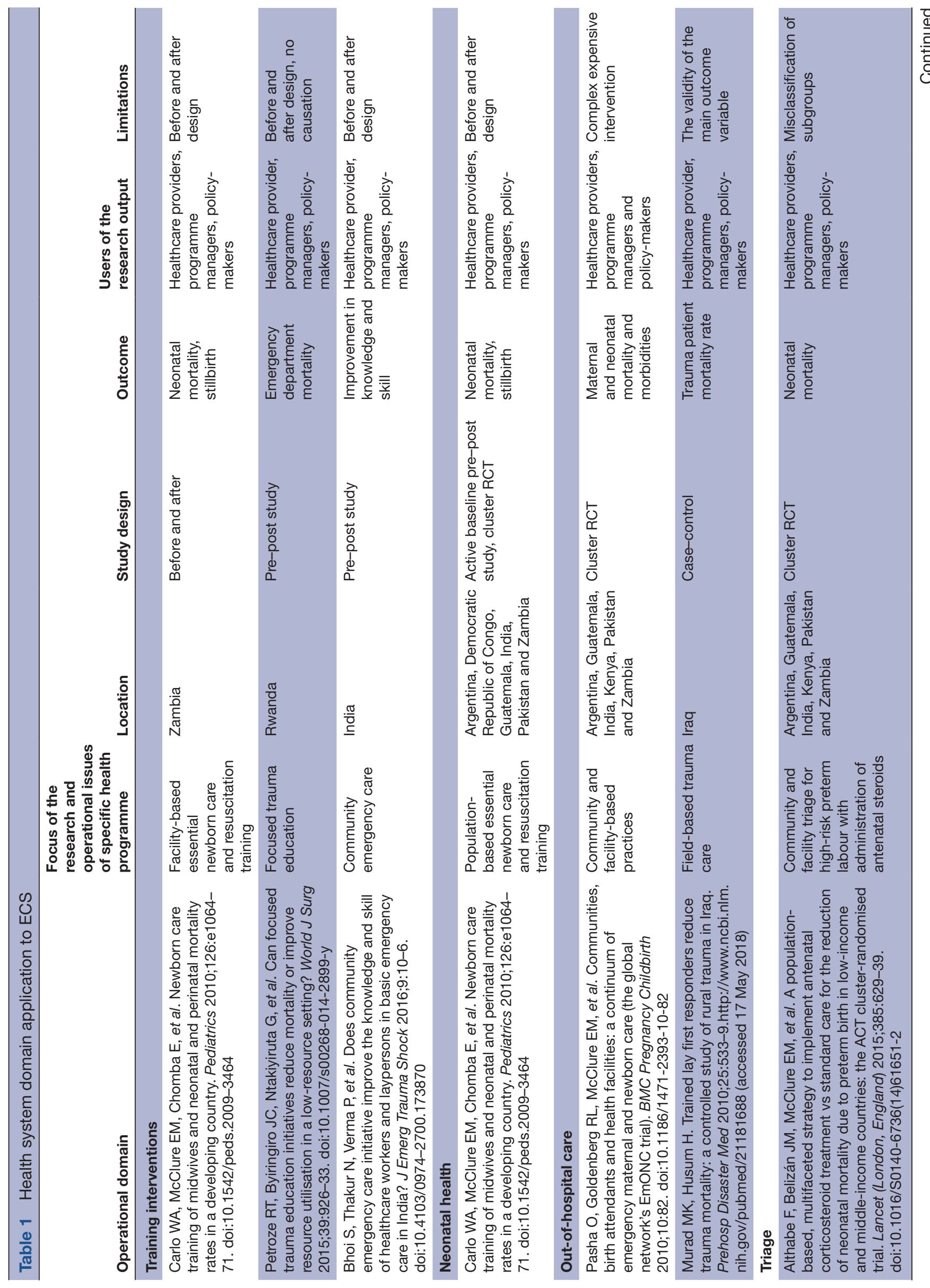

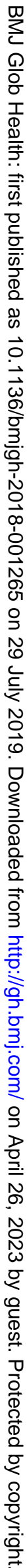



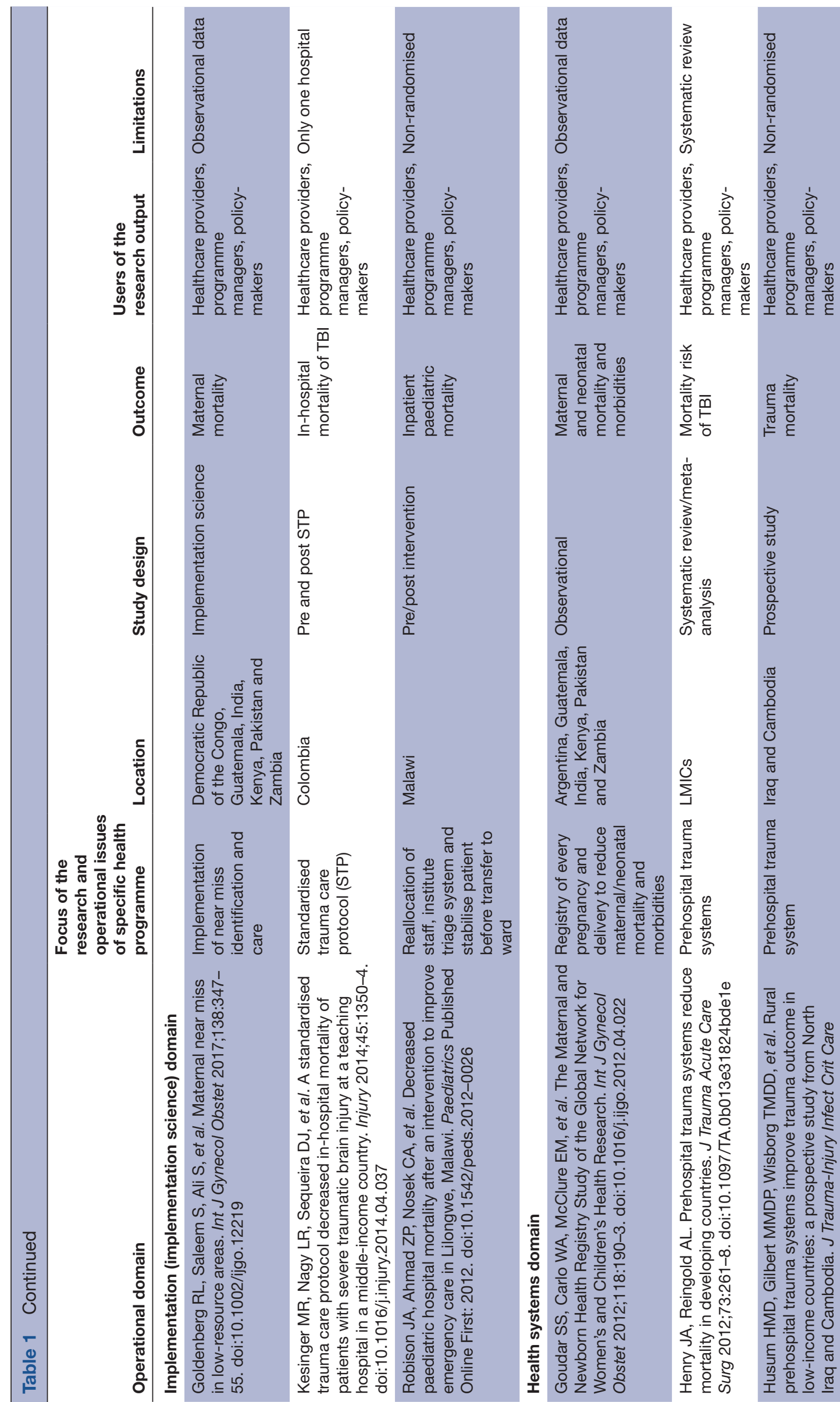

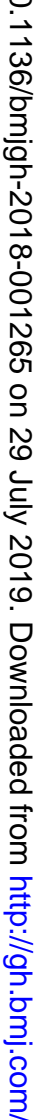
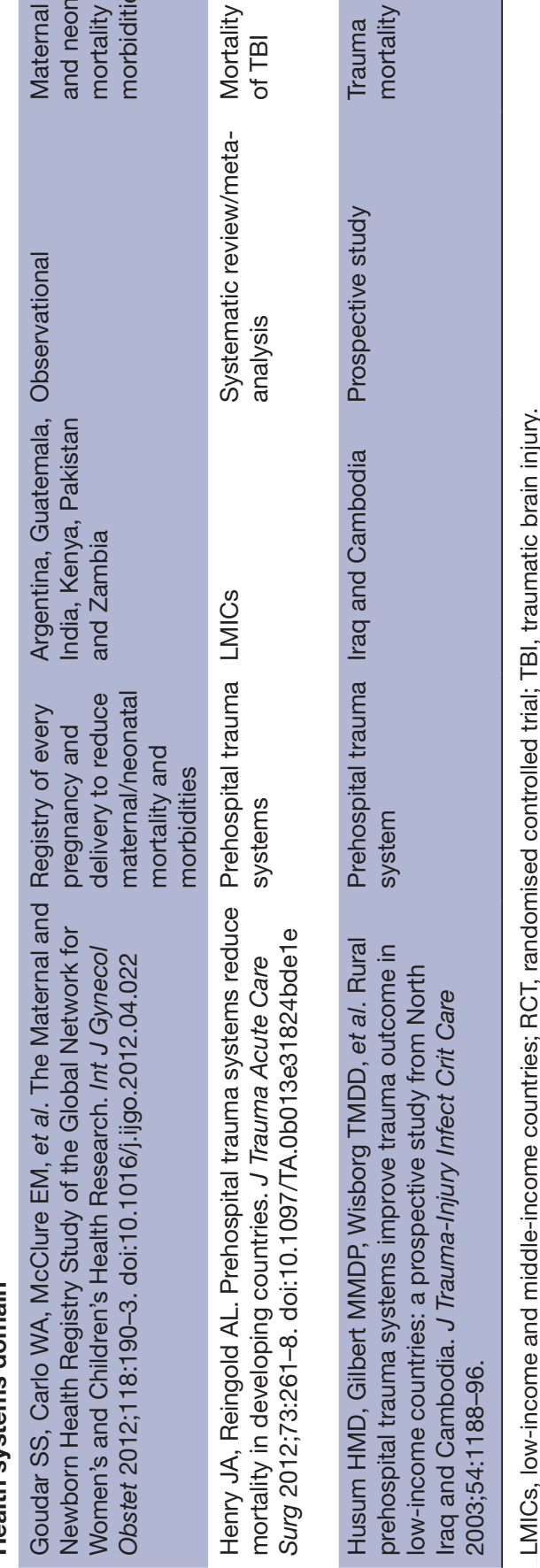
2. Are these questions locally driven and applicable to local health policy and systems?

3. Can the research be designed to obtain generalisable data?

4. Are context appropriate human-centred design methodologies ${ }^{49}$ being widely applied?

5. How can respectful client care research elucidate acute care health-seeking behaviour and outcomes?

6. Since poor quality of healthcare is a major driver of excess mortality across acute conditions, how can this be addressed in the context of universal healthcare coverage? ${ }^{36}$

Several limitations may be contributing to a scarcity of output regarding ECS and HPSR in LMICs. Examples include limited funds for health systems research, a focus on vertical programming and primary care which did not adequately integrate referral or ECS, and a focus on process research which does not adequately embed science or hybrid designs. Also, human-centred design approaches have been both underfunded and underused. ${ }^{31}$ These limitations drive investigators from countries of all income levels to focus on donor-driven agendas targeted to specific outputs and outcomes, rather than on CAS ECS research. In addition to being constrained by funding, there is insufficient comparable high-quality primary and secondary data to appropriately and consistently answer these research questions. ${ }^{621}$ Limited longitudinal data collecting systems are in place for ECS population-based data and not routinely collected by demographic and health surveys, ministries of health, non-governmental organisations or other agencies, which then limits the comparability of these data.

Another limitation is that ECS HPSR requires systems research experience and ECS-specific expertise capacity at various institutional and individual levels. Similarly, the lack of local emergency medicine development and the corresponding lack of capacity in relevant governmental agencies and academic departments is exacerbated by limited governmental research directorates, ethical review boards or policy guidance that pose challenges for HPSR research in general.

Finally, while beyond the scope of this paper, certain ethical concerns are particularly salient in the context of emergency care research in LMICs. These include (1) risk-benefit assessment and standards of care for participants with elevated baseline risk, (2) blurring of the roles of clinician and researcher, (3) populations with intersecting vulnerabilities, (4) fair participant selection, (5) quality of consent and (6) community engagement to name a few. ${ }^{50}$ In addition, thinking about who is commissioning the research and how the findings will be used are some of the questions that only scratch the surface of ethical considerations.

\section{CONCLUSION}

ECS are CAS that present diverse research and intervention challenges, particularly in resource-constrained settings. Funding, ethical considerations, conceiving and executing a context-grounded programme design all represent challenges. However, the potential impact of research that uses such a framework on evolving ECS in LMICs could have a tremendous influence on optimising systems to impact morbidity and mortality. In this paper, we present an ECS-specific research framework that references already-established frameworks. In this framework, we articulate distinct domains for ECS but also highlight research that is integrated either across ECS domains-linking software and hardware components where feasible-or across points and levels of service, with consideration given to the outcomes of community-based, prehospital and facility-based care. For the studies and systematic reviews of interventions that meet these qualifications, we carefully consider their limitations to inform and guide researchers studying ECS moving forward.

\section{Author affiliations}

${ }^{1}$ sidHARTe — Strengthening Emergency Systems Program, Columbia University Heilbrunn Department of Population and Family Health, New York, New York, USA ${ }^{2}$ Department of Emergency Medicine, Columbia University College of Physicians and Surgeons, New York, New York, USA

${ }^{3}$ Department of Emergency Medicine, Johns Hopkins University School of Medicine, Baltimore, Maryland, USA

${ }^{4}$ Department for Management of Noncommunicable Diseases, Disability, Violence and Injury Prevention, World Health Organization, Geneva, Switzerland

${ }^{5}$ Division of Emergency Medicine, University of Cape Town, Cape Town, South Africa ${ }^{6}$ Accident and Emergency Department, Aga Khan University, Nairobi, Kenya

${ }^{7}$ Adult Emergency and Trauma Centre, Queen Elizabeth Central Hospital, Ministry of Health, Blantyre, Malawi

${ }^{8}$ Emergency Medicine Section, Internal Medicine Department, College of Medicine, University of Malawi, Blantyre, Malawi

${ }^{9}$ Department of Pediatrics, Division of Neonatology, University of Alabama at Birmingham, Birmingham, Alabama, USA

${ }^{10}$ Department of Emergency Medicine and Center for Global Health, University of Illinois at Chicago, College of Medicine, Chicago, Illinois, USA

${ }^{11}$ Department of Emergency Medicine, All India Institute of Medical Sciences, New Delhi, India

${ }^{12}$ Department of Emergency Medicine, University of Colorado School of Medicine, Aurora, Colorado, USA

Acknowledgements We would like to acknowledge Nalini P Anand, JD, MPH, Division of International Science Policy, Planning and Evaluation and Director, Center for Global Health Studies at the Fogarty International Center, National Institutes of Health for her dedication, support and technical guidance throughout this process. We would also like to thank Blythe Beecroft for her outstanding organisational and interpersonal skills. We also acknowledge Drs Matt Strehlow and Stephen Hargarten for their contributions to the initial process. Finally, we would like to acknowledge Jamie M.S. Greenberg, MPH for providing copyediting and referencing support for this paper.

Collaborators Jamie M.S. Greenberg, National Institute of Health Fogarty International Center convened the Collaborative on Enhancing Emergency Care Research in LMICs (CLEER).

Contributors All listed authors contributed to the planning, conduct and reporting of the work presented in the manuscript.

Competing interests None declared.

Patient consent for publication Not required.

Provenance and peer review Not commissioned; externally peer reviewed.

Data sharing statement № additional data are available.

Open access This is an open access article distributed in accordance with the Creative Commons Attribution Non Commercial (CC BY-NC 4.0) license, which permits others to distribute, remix, adapt, build upon this work non-commercially, and license their derivative works on different terms, provided the original work is properly cited, appropriate credit is given, 
any changes made indicated, and the use is non-commercial. See: http:// creativecommons.org/licenses/by-nc/4.0

\section{ORCID iD}

Lily A Wendle http://orcid.org/0000-0001-5903-0165

\section{REFERENCES}

1 Thind A, Hsia R, Mabweijano J, et al. Prehospital and emergency care, 2015. Available: http://www.ncbi.nlm.nih.gov/pubmed/ 26741008 [Accessed 17 May 2018].

2 Hirshon JM, Risko N, Calvello EJB, et al. Health systems and services: the role of acute care. Bull World Health Organ 2013;91:386-8.

3 Marsh RH, Rouhani SA. Gaps in physical access to emergency care in sub-Saharan Africa. Lancet Glob Health 2018;6:e240-1.

4 Moresky RT, Bisanzo M, Rubenstein BL, et al. A research agenda for acute care services delivery in low- and middle-income countries. Acad Emerg Med 2013;20:1264-71.

5 Ouma PO, Maina J, Thuranira PN, et al. Access to emergency hospital care provided by the public sector in sub-Saharan Africa in 2015: a geocoded inventory and spatial analysis. Lancet Glob Health 2018;6:e342-50.

6 Kruk ME, Kelley E, Syed SB, et al. Measuring quality of health-care services: what is known and where are the gaps? Bull World Health Organ 2017;95:389-389A.

7 Kruk ME, Larson E, Twum-Danso NAY. Time for a quality revolution in global health. Lancet Glob Health 2016;4:e594-6.

8 Kruk ME, Freedman LP. Assessing health system performance in developing countries: a review of the literature. Health Policy 2008;85:263-76.

9 Chang CY, Abujaber S, Reynolds TA, et al. Burden of emergency conditions and emergency care usage: new estimates from 40 countries. Emerg Med J 2016;33:794-800.

10 Calvello EJB, Broccoli M, Risko N, et al. Emergency care and health systems: consensus-based recommendations and future research priorities. Acad Emerg Med 2013;20:1278-88.

11 Adam T, de Savigny D. Systems thinking for strengthening health systems in LMICs: need for a paradigm shift. Health Policy Plan 2012;27:3-5.

12 Bennett S, Agyepong IA, Sheikh K, et al. Building the field of health policy and systems research: an agenda for action. PLoS Med 2011;8:1-5.

13 World Health Organization. Systems thinking for health systems strengthening. Autophagy 2009;7:1-112

14 WHO. Everybody's business: strengthening health systems to improve health outcomes: WHO's framework for action. Production 2012;2007:1-56

15 de Savigny D, Blanchet K, Adam T. Applied systems thinking for health systems research: a methodological handbook, 2017. Available: http://researchonline.Ishtm.ac.uk/4646083/ [Accessed 17 May 2018]

16 Adam T, Hsu J, de Savigny D, et al. Evaluating health systems strengthening interventions in low-income and middle-income countries: are we asking the right questions? Health Policy Plan 2012;27:iv9-19.

17 Agyepong IA, Kodua A, Adjei S, et al. When 'solutions of yesterday become problems of today': crisis-ridden decision making in a complex adaptive system (CAS) - the Additional Duty Hours Allowance in Ghana. Health Policy Plan 2012;27(suppl 4):20-31.

18 Mutale W, Balabanova D, Chintu N, et al. Application of system thinking concepts in health system strengthening in low-income settings: a proposed conceptual framework for the evaluation of a complex health system intervention: the case of the BHOMA intervention in Zambia. J Eval Clin Pract 2016;22:112-21.

19 Fouda A, Paolucci F. Path dependence and universal health coverage: the case of Egypt. Front Public Health 2017;5:1-8.

20 Blanchet K, James P, do Hto. How to do (or not to do) ... a social network analysis in health systems research. Health Policy Plan 2015;27:438-46.

21 Tunçalp Ö, Were WM, MacLennan C, et al. Quality of care for pregnant women and newborns-the WHO vision. BJOG 2015;122:1045-9.

22 Akachi Y, Kruk ME. Quality of care: measuring a neglected driver of improved health, 2017: 465-72.

23 Bryce J, Requejo JH, Moulton LH, et al. A common evaluation framework for the African Health Initiative. BMC Health Serv Res 2013;13.
24 Fox AM, Reich MR. The politics of universal health coverage in lowand middle-income countries: a framework for evaluation and action. $\checkmark$ Health Polit Policy Law 2015;40:1023-60.

25 Jahanmehr N, Rashidian A, Khosravi A, et al. A conceptual framework for evaluation of public health and primary care system performance in Iran. Glob J Health Sci 2015;7.

26 Van OJ, Criel B, Bhojani U, et al. The health system dynamics framework: the introduction of an analytical model for health system analysis and its application to two case-studies. Heal Cult Soc 2012;2:1-21.

27 Remme JHF, Adam T, Becerra-Posada F, et al. Defining research to improve health systems. PLoS Med 2010;7.

28 Wilkinson J, Goff M, Rusoja E, et al. The application of systems thinking concepts, methods, and tools to global health practices: an analysis of case studies. J Eval Clin Pract 2017;24:1-12.

29 Reynolds TA, Sawe H, Rubiano AM, et al. Strengthening health systems to provide emergency care. In: Disease control priorities: improving health and reducing poverty. The World Bank 2018:247-65.

30 Plsek PE, Wilson T. Complexity science: complexity, leadership, and management in healthcare organisations. BMJ 2001;323:746-9.

31 World Health Organization. WHO global strategy on people-centred and integrated health services: interim report, 2015. Available: http:// apps.who.int/iris/bitstream/handle/10665/155002/WHO HIS SDS 2015.6_eng.pdf?sequence=1\&isAllowed=y\%0Ahttp://apps.who.int/iris/ bitstream/10665/155002/1/WHO_HIS_SDS_2015.6_eng.pdf\%0Ahttp:// www.who.int/servicedeliverysafety/areas/people-centred-care/gl

32 Cordon CP. System theories: an overview of various system theories and its application in healthcare. Am J Syst Sci 2013;2:13-22.

33 Sheikh K, Ranson MK, Gilson L. Explorations on people centredness in health systems. Health Policy Plan 2014;29:ii1-5.

34 Aberese-Ako M, van Dijk H, Gerrits T, et al. 'Your health our concern, our health whose concern?': perceptions of injustice in organizationa relationships and processes and frontline health worker motivation in Ghana. Health Policy Plan 2014;29:ii15-28.

35 Campbell OMR, Calvert C, Testa A, et al. The scale, scope, coverage, and capability of childbirth care. Lancet 2016;388:2193-208.

36 Orgill M, Nxumalo N, Amde W, et al. Health policy and systems research. South African Heal Rev 2012:151-60.

37 Sherr K, Fernandes Q, Kanté AM, et al. Measuring health systems strength and its impact: experiences from the African Health Initiative. BMC Health Serv Res 2017;17(Suppl 3).

38 Gilson L. Introduction to health policy and systems research. In: Health policy and systems research a methodology reader, 2012: 21-40.

39 Ellokor S, Olckers P, Gilson L, et al. Crises, routines and innovationsthe complexities and possibilities of sub-district management. In: Padarath A, English E, eds. South African health review. Durban, South Africa: Health Systems Trust, 2013.

40 Kruk ME, Gage AD, Joseph NT, et al. Mortality due to lowquality health systems in the universal health coverage era: a systematic analysis of amenable deaths in 137 countries. Lancet 2018;392:2203-12.

41 Husum H, Gilbert M, Wisborg T, et al. Rural prehospital trauma systems improve trauma outcome in low-income countries: a prospective study from North Iraq and Cambodia. J Trauma 2003;54:1188-96.

42 Bills CB, Newberry JA, Darmstadt G, et al. Reducing early infant mortality in India: results of a prospective cohort of pregnant women using emergency medical services. BMJ Open 2018;8:e019937.

43 Walker R, Auerbach PS, Kelley BV, et al. Implementing an emergency medical services system in Kathmandu, Nepal: a model for "white coat diplomacy". Wilderness Environ Med 2014;25:311-8.

44 Molyneux E, Ahmad S, Robertson A. Improved triage and emergency care for children reduces inpatient mortality in a resource-constrained setting. Bull World Health Organ 2006;84:314-9.

45 Kruk ME, Gage AD, Arsenault C, et al. High-quality health systems in the sustainable development goals era: time for a revolution. Lancet Glob Health 2018;6:e1196-252.

46 Kironji AG, Hodkinson P, de Ramirez SS, et al. Identifying barriers for out of hospital emergency care in low and low-middle income countries: a systematic review. BMC Health Serv Res 2018;18.

47 Curran; GM, Bauer M, Mittman B, et al. Effectiveness-implementation hybrid design: combining elements of clinical effectiveness and implementation research to enhance public health. Med Care 2012;50:217-26.

48 Ghaffar A, Langlois EV, Rasanathan K, et al. Strengthening health systems through embedded research. Bull World Health Organ 2017;95.

49 Yoshida S. Approaches, tools and methods used for setting priorities in health research in the 21st century. J Glob Health 2016;6.

50 Millum J, Beecroft B, Hardcastle TC, et al. Emergency care research ethics in low- and middle-income countries. BMJ Glob Heal. 